\title{
LA UTILIZACIÓN DEL DISCURSO ANTIMASÓNICO COMO ARMA POLÍTICA DURANTE EL PRIMER FRANQUISMO (1939-1945)
}

\author{
JAVIER DOMÍNGUEZ ARRIBAS \\ École des Hautes Études en Sciences Sociales, París
}

RESUMEN: El artículo trata sobre el uso que se bizo durante el primer franquismo, en el seno de la coalición que habia ganado la guerra civil, de la identificación del adversario con la masonería. En una primera parte se analiza el contenido, la intencionalidad $y$ el origen de tres falsos documentos masónicos que fueron utilizados para desprestigiar colectivamente a distintas facciones de la coalición franquista. En la segunda parte se estudian los casos de diversas personalidades del régimen que fueron acusadas de tener relación con la masonería. Se presta además una atención especial al caso de Gerardo Salvador Merino.

PALABRAS Clave: Discurso antimasónico. Falsos documentos. Gerardo Salvador Merino. Primer franquismo. España, 19391945.

ABSTRACT: This paper discusses the use made between 1939 and 1945 within the coalition which had won the Spanish Civil War of the identification of the adversary with freemasonry. The first part analyses the content, aims and origin of three false masonic documents that were used to discredit, in a general way, different factions within the francoist coalition. The second part studies the cases of diverse personalities within the regime who were accused of masonic links. Special attention is paid to the case of Gerardo Salvador Merino.

KEY WORDS: Antimasonic discourse. False documents. Gerardo Salvador Merino. Francoism. Spain, 1939-1945.

En octubre de 1941, un alto cargo del régimen franquista fue procesado y condenado por el Tribunal Especial para la Represión de la Masonería y del Comunismo. Había sido acusado unos meses antes del delito de masonería, que 
estaba penado en virtud de la Ley de 1 de marzo de 1940. Aunque su caso fue el que tuvo consecuencias más graves, Gerardo Salvador Merino no fue una excepción. Otras personalidades del bando vencedor en la guerra civil, e incluso facciones enteras del mismo, también fueron puestas en entredicho por la acusación de tener vínculos con la masonería. Sin embargo, los escasos trabajos existentes acerca del antimasonismo de los inicios de la dictadura apenas han prestado atención a esta problemática ${ }^{1}$. Y nos hallamos ante un tema que podría decirnos mucho, no sólo sobre los usos políticos del discurso antimasónico, sino también sobre las propias dinámicas internas de la coalición autoritaria franquista. Por estas razones, parece pertinente estudiar la utilización que se hizo, en el seno del régimen, de la identificación del adversario con la masonería. De ello se ocuparán las páginas que siguen.

La acusación de tener o haber tenido vínculos con la «secta masónica» halló su caldo de cultivo ideal en la primera etapa del régimen de Franco. Terminada la guerra civil, y aun antes, las distintas familias políticas del bando vencedor (falangistas, carlistas, monárquicos, católicos), con sus correspondientes facciones internas, iniciaron una prolongada disputa por imponer su ideario y, sobre todo, por obtener la mejor parte en el reparto de parcelas de poder. En este marco, cualquier procedimiento que permitiera debilitar al adversario político iba a ser puesto en práctica. Y el discurso antimasónico imperante en la zona sublevada desde julio de 1936 proporcionaba a las distintas facciones una herramienta que podía revelarse muy rentable. Según la propaganda oficial, la masonería, junto al judaísmo y al comunismo, era la responsable de todos los males de España y se caracterizaba, entre muchos otros rasgos, por su capacidad para infiltrarse entre sus enemigos. La idea de la infiltración masónica hacía posible la identificación del oponente con la masonería, aunque éste formara parte de la coalición autoritaria franquista. Tal identificación, por ligera que fuese, podía tener consecuencias muy serias en un contexto en el que el discurso antimasónico había venido acompañado por una represión meticulosa de los masones españoles.

Este trabajo se compone de dos partes claramente diferenciadas, en las que se estudiarán dos modalidades distintas de la misma acusación. En la primera, serán analizados varios documentos atribuidos a la masonería que fueron utilizados por distintos grupos de la coalición vencedora de la guerra civil como un arma arrojadiza contra las facciones políticas enemigas que formaban parte de esa misma coalición. En la segunda parte, se estudiarán varios casos de personalidades concretas del régimen que fueron acusadas de tener vínculos con la masonería, y se dedicará una atención especial a Gerardo Salvador Merino.

1 Véanse algunas reflexiones al respecto en PÉREZ LÓPEZ, Pablo: «La Masonería en la Prensa Confesional en Castilla durante la Segunda República y la Guerra Civil: Diario Regional de Valladolid 1931-39», en FERRER BENIMELI, J. A. (coord.): Masonería, revolución y reacción, Alicante, 1990, vol. I, pp. 391-409 (especialmente, p. 405); y en Morales RuIZ, Juan José: «Retórica y represión, en la Prensa de postguerra. El discurso antimasónico del franquismo», en FerRer BENIMELI, J. A. (coord.): La Masonería Española entre España y América, Zaragoza, 1995, vol. II, pp. 695-728. 


\section{LOS FALSOS DOCUMENTOS MASÓNICOS}

\section{El «Mensaje del Gran Oriente»}

El primer supuesto documento masónico que va a ser analizado es el «Mensaje del Gran Oriente Español a la Asociación Masónica Internacional», fechado en París el 10 de marzo de $1939^{2}$. Veamos su contenido con detalle. En la primera mitad del texto se afirma que, a pesar de las medidas represivas aprobadas por el nuevo régimen, «se nos presenta consolador el porvenir masónico de estos Valles». Las gestiones de los «hermanos» en los círculos del poder habrían permitido atenuar la persecución antimasónica, lo que se intenta demostrar mediante la reproducción de cuatro documentos oficiales relativos a la represión de la masonería. En la segunda mitad del apócrifo se informa a la Asociación Masónica Internacional (AMI) de los pasos dados por el Gran Oriente para cumplir las órdenes de aquélla y lograr una infiltración generalizada en el nuevo Estado franquista, y muy particularmente en Falange Española Tradicionalista y de las JONS, con el objeto de convertirla en un organismo «al servicio de la Masonería [.... mediante la ocupación de puestos dirigentes» ${ }^{3}$. Entre las medidas mencionadas por el texto tendentes a favorecer dicha infiltración, cabe citar las siguientes: la falsificación de documentos oficiales, el acatamiento aparente del «llamado Movimiento Nacional», la creación de una red de logias racistas y «la publicación de artículos y folletos de orientación izquierdista pero entusiásticamente falangista». La infiltración sistemática se habría producido ya en distintos organismos y cuerpos del nuevo régimen, tales como el Sindicato Español Universitario (SEU), el Servicio Español del Magisterio, las Organizaciones Juveniles, «el personal especializado que procede a la clasificación de documentos y a censura de correo» o los cuerpos de funcionarios «militares, judiciales, docentes y bibliotecarios» ${ }^{4}$. Otras acciones llevadas a cabo por el Gran Oriente iban dirigidas a unir a los enemigos de Franco, a «fomentar el descontento» o a «exasperar a los "requetés" mediante la sugerencia de restauración liberal proyectada por el Caudillo y patrocinada por el Ministro de la Gobernación "Serrano Suñer"»"

2 Existen diferentes versiones de este documento, de las que hablaremos más tarde. Una de ellas ha sido reproducida en Documentos Inéditos para la Historia del Generalísimo Franco (en adelante, Documentos Inéditos), Madrid, 1992-1994, vol. I, pp. 312-322. Otra versión es mencionada por Tusell, Javier: Franco en la guerra civil. Una biografía política, Barcelona, 1993, p. 380. El texto ocupa unas cinco páginas mecanografiadas a un espacio. Por otro lado, conviene aclarar aquí que no me detendré en demostrar la falsedad — más que evidente - de ninguno de los supuestos documentos masónicos analizados a lo largo de este trabajo.

3 Documentos Inéditos, I, p. 319.

4 Archivo General de la Guerra Civil Española (en lo sucesivo, AGGCE), Masonería, A, leg. 350, exp. 15 .

5 Documentos Inéditos, I, p. 321. 
El «Mensaje del Gran Oriente» circuló en distintas esferas del nuevo poder franquista durante buena parte de 1939. Su difusión comenzó probablemente en torno al final de la guerra civil y, en todo caso, no antes de la fecha que aparecía en el documento (10 de marzo de 1939), como es lógico. Una copia del texto llegó a manos de Franco $^{6}$; otras fueron repartidas entre los ministros y diversas autoridades 7 . La Delegación del Estado para Recuperación de Documentos, organismo encargado de clasificar la documentación masónica, también recibió un ejemplar ${ }^{8}$. Es decir, el texto fue copiado una y otra vez a lo largo de varios meses, lo que explica la existencia de diferencias entre unas versiones y otras. Así, la copia que se conserva en el archivo de Franco parece ser más fiel al desconocido original que la del servicio de Recuperación de Documentos, pues tiene menos incoherencias y alguna precisión más. Pero la única diferencia significativa entre estas dos versiones es que en la segunda han desaparecido todas las alusiones a la infiltración masónica en los medios docentes y bibliotecarios, dos cuerpos dependientes del Ministerio de Educación Nacional. Quizá sea una coincidencia; quizá un olvido intencionado destinado a no manchar la reputación de un ministerio que hasta abril de 1939 había sido dirigido por un personaje - Pedro Sainz Rodríguez- que durante mucho tiempo fue víctima de rumores que le relacionaban con la masonería. Pero de esta cuestión hablaremos más tarde.

Una versión resumida del «Mensaje del Gran Oriente» circuló durante el verano de 1939, al menos en Barcelona y Baleares. En ella sólo eran reproducidos los párrafos que aludían a la infiltración masónica en la Falange y en los organismos que dependían de ésta9. Otra versión muy similar del texto alcanzó probablemente una difusión algo mayor, pues circuló en forma de hoja volandera, esta vez impresa, durante el otoño de 1939. El pasquín reproducía la versión corta que acabo de mencionar, centrada en la infiltración de la masonería en Falange, y terminaba con un llamamiento dirigido a los españoles: «iGuerra a la masonería, donde esté! En la Universidad, en las fábricas, en las oficinas y

6 Es la versión publicada en Documentos Inéditos (I, pp. 312-322) y citada por SUÁREZ FERNÁNDEZ, L.: Francisco Franco y su tiempo, Madrid, 1984, vol. III, p. 93. Este autor afirma que el documento fue «interceptado por los servicios secretos españoles» y que «no puede considerarse como absolutamente fidedigno».

7 Así lo afirma TUSELL (Franco, op. cit., p. 380), que ha consultado la copia que se encuentra en el archivo del general Varela, una de las personalidades que debió de recibir el documento. Hay además indicios para pensar que el cardenal Gomá también tuvo conocimiento del texto. Cfr. MARQuina BARrio, Antonio: La diplomacia vaticana y la España de Franco (1936-1945), Madrid, 1983, p. 210.

8 Es la copia que se conserva en el AGGCE, Masonería, A, leg. 350, exp. 15.

9 El Servicio de Información y Policía Militar (SIPM) fue informado por sus delegaciones territoriales de la existencia del escrito, y el 20 de julio de 1939 remitía sendas copias de esta versión corta del documento a Serrano Súñer, Ministro de la Gobernación, y a Marcelino de Ulibarri, Delegado del Estado para Recuperación de Documentos. Archivo General Militar de Ávila (en lo sucesivo AGM), caja 2986, exp. 6. 
en los más altos puestos, se ha de dar virilmente por todos los buenos españoles, este grito: iMUERA LA MASONERÍA!» ${ }^{10}$. El informe que acerca de este asunto envió el Delegado Nacional de Información e Investigación de FET —a la sazón José Finat - al Secretario General de la organización nos permite reconstruir el origen, la difusión y la intencionalidad de esta hoja volante en particular, pero también del "Mensaje del Gran Oriente» en general. El pasquín impreso fue distribuido al menos en Sevilla y su provincia durante octubre de 1939. Y no es ninguna sorpresa que todos los implicados en la difusión de la hoja tuvieran alguna relación con la oficialmente extinguida Comunión Tradicionalista. Según el citado informe, estaban involucradas en el asunto las siguientes personas: un miembro de la Comunión, el antiguo conserje del Círculo Tradicionalista, el director del Museo del Requeté de Sevilla, un maestro carlista y un dominico canario vinculado al requeté y a la Junta Carlista de Guerra. Aunque uno de los implicados declaró que había recibido las hojas en un paquete procedente de Bilbao, los investigadores de FET sospechaban que éstas habían sido impresas en Sevilla.

No hay duda, pues, de que los carlistas estaban detrás de la elaboración y distribución de esta hoja clandestina, y es más que probable que fueran también los responsables de la fabricación del documento original en que se basaba ésta, es decir, el «Mensaje del Gran Oriente». En cualquier caso, habían contribuido a su difusión inicial en círculos restringidos, como ya indicaba el informe de Finat al referirse a una copia de la primera versión del apócrifo:

Luego ha resultado que la misma llegó a Pedro Gamero por conducto de una persona allegada a un significado elemento tradicionalista de la fracción [sic] disidente de FAL CONDE, que poseía el documento o copia del mismo y cuya persona había hecho varias copias para enviarlas a distintas personalidades ${ }^{11}$.

En definitiva, si nos preguntamos por el origen del documento, todos los indicios apuntan hacia los carlistas, y en particular — como señala el fragmento citado- hacia los partidarios de Manuel Fal Conde, opuestos a la colaboración con el régimen de Franco. No es casualidad que la hoja mencionada circulara en Sevilla, ya que esta ciudad era el principal núcleo del tradicionalismo no colaboracionista y, además, el lugar de origen de Fal Conde.

La intencionalidad del «Mensaje del Gran Oriente» es clara: el argumento de la infiltración masónica (sobre todo en FET y de las JONS) era empleado en primer lugar para atacar a los falangistas, principales beneficiarios de la unificación de abril de 1937. Recordemos que el documento aludía a la infiltración de la masonería en organismos monopolizados por los falangistas, como el SEU o las Organizaciones Juveniles. El citado informe de la Delegación Nacional de

10 Archivo General de la Administración (AGA), Presidencia, 52/14106, 26 de octubre de 1939.

11 Ibidem. Mayúsculas en el original. 
Información e Investigación no erraba al interpretar la intención de los autores de la hoja clandestina de Sevilla, la cual sólo recogía «la parte de aquel mensaje [del Gran Oriente] en lo que se refiere a F.E.T. y de las J.O.N-S.» El informe seguía así:

Como se pude [sic] deducir por lo impreso en la misma, el escoger los párrafos referidos, revela la intención del que la mandó imprimir, no de combatir a la masonería, sino de sembrar la duda sobre la Organiación [sic], propósito que a más de ser delictivo, lo es más teniendo en cuenta que sirve inconscientemente a los fines de la masonería ${ }^{12}$.

Podemos hacer extensible tal interpretación a la versión inicial del «Mensaje del Gran Oriente». Pero con ésta no sólo se pretendía «sembrar la duda» sobre el partido único, sino también sobre el régimen en su conjunto, que no salía muy bien parado en el documento. Es posible incluso que, en su ataque, los presuntos autores falcondistas del «Mensaje del Gran Oriente» no olvidaran a la otra gran facción del tradicionalismo. Así parece indicarlo el hecho de que el escrito mencione la infiltración masónica entre el personal encargado de la «clasificación de documentos», un servicio estatal copado por los carlistas navarros colaboracionistas ${ }^{13}$.

Pero la intencionalidad de un documento como éste sólo adquiere plena coherencia si la consideramos a la luz del contexto en que surgió. El Decreto de Unificación de abril de 1937 había creado un partido único — FET y de las JONS - en el que los falangistas pasaron a ser predominantes, mientras que los carlistas fueron progresivamente postergados. La consiguiente lucha por el reparto de parcelas de poder dio lugar, desde 1937, a continuos incidentes entre las dos facciones, que aumentaron sensiblemente a medida que se aproximaba la victoria de las tropas de Franco. Cuando terminó la guerra, las tensiones entre los dos principales componentes de FET, hasta cierto punto contenidas antes para no perjudicar el esfuerzo bélico, salieron completamente a la superficie. Y el final de la guerra es precisamente el marco en que fue redactado el «Mensaje del Gran Oriente». Había sido concebido, pues, como un arma política antifalangista que expresaba el descontento de los carlistas, y en particular de aquéllos más reacios a la unificación ${ }^{14}$.

12 Ibidem.

13 La denominación «clasificación de documentos» sólo puede referirse a la Delegación del Estado para Recuperación de Documentos, dirigida por el carlista colaboracionista Marcelino de Ulibarri.

14 Sobre las tensiones entre carlistas y falangistas, véanse, por ejemplo, CANAL, Jordi: $E l$ carlismo. Dos siglos de contrarrevolución en España, Madrid, 2000, pp. 340-344; y TuselL: Franco, op. cit., pp. 298-300. No era la primera vez que los carlistas lanzaban acusaciones de masonismo contra antiguos aliados. Ya lo habían hecho en 1888, con motivo de la escisión integrista. Cfr. CANAL, Jordi: «La masonería en el discurso integrista español a fines del siglo XIX: Ramón Nocedal y Romea», en FERRER BENIMELI (coord.): Masonería, revolución y reacción, op. cit., vol. II, pp. 771-791. 


\section{Las «Máximas e instrucciones»}

Otro texto apócrifo atribuido a la masonería son las llamadas «Máximas e instrucciones políticas para todo el Gran Oriente Español y todas las logias de la Masonería Egipciana». Aunque el documento no está datado, probablemente fue elaborado durante la segunda mitad de 1940, como se verá más adelante. Para empezar, conviene exponer un resumen por temas de su extenso contenido $^{15}$. En las setenta instrucciones que componen el texto aparecen, sin orden aparente, cuatro grandes líneas de actuación supuestamente destinadas a los masones españoles, con el objeto de que se adapten a las nuevas circunstancias (tras «el terrible golpe recibido») y preparen la revolución. La infiltración en diversas esferas de poder es quizá la primera de esas consignas: «Se trabajará por los hermanos cerca del Jefe de Gobierno, para que los Ministerios y principales empleos de la Nación, recaigan en personas de nuestra orden». Si ello no se logra, se procurará que accedan a esos cargos personas «de poco talento» que puedan ser manipuladas fácilmente desde puestos subalternos ${ }^{16}$. En el caso del Ejército, la infiltración es ya una realidad — según el documento- que debe profundizarse mediante la incorporación de izquierdistas a sus filas, para lograr así «su inutilidad para la causa contraria» ${ }^{17}$. La Iglesia, en todos sus niveles, es otro objetivo de la infiltración masónica. Si no se consiguiera situar a adeptos en las jerarquías, sería conveniente al menos que éstas fueran ocupadas por personas incompetentes que por sí mismas desprestigien la institución. Otro ámbito preferente de intervención masónica - ya sea ésta directa o indirectaes la administración de justicia. El objetivo, en este caso, es obtener la impunidad de los masones. Tal infiltración generalizada facilitaría el cumplimiento de una segunda directriz que también se repite a lo largo de todas las «Máximas»: la promoción del descontento, de la división y del descrédito del Gobierno. Los masones «se dedicarán a encender las pasiones de los partidos con constancia, y cauetela, [sic] contrariar a los gobiernos, desconceptuarlos y propagar noticias o rumores, que engrián o abatan, segun convenga» ${ }^{18}$. En tercer lugar, la Falange es presentada como el principal enemigo de la masonería. Debe ser por ello combatida por todos los medios, hasta neutralizar su acción y lograr que sea disuelta. La máxima 44 resume estas consideraciones al aludir al futuro cumplimiento de los planes masónicos:

15 El texto ocupa entre siete y nueve páginas mecanografiadas a un espacio, según las versiones. Una de ellas ha sido reproducida por AlmuiñA, Celso: «Los orígenes de la Guerra Civil. El asesinato de Calvo Sotelo y la Masonería», en FERRER BENIMELI, J. A. (coord.): La masonería en la España del siglo XX, Toledo, 1997, vol. II, pp. 971-1027. Yo he preferido seguir una versión algo más coherente y probablemente anterior que se encuentra en el AGGCE, Masonería, A, leg. 350, exp. 15. Será la que citaré preferentemente a lo largo de este trabajo.

16 Máxima 11. Subrayado en el original.

17 De esta manera, «o no tendremos quien nos contrarreste o tendremos en el ejército masónderechista nuestro mejor apoyo» (máxima 62).

18 Máxima 9. Se ha respetado la ortografía y acentuación del original. 
como sólo podría impedirlo la labor eficaz de la falange, nuestro principal estudio ha de ser el combatirla calumniándola desacreditándola, y aun exponiendola con arte a que cometa excesos que la hagan odiosa, a fin de que el Jefe le ponga un reglamento que la arruine y acabe por ser disuelta, y vencidos sus partidarios ${ }^{19}$.

En suma, «se ha de dirigir el ataque más fuerte y empeñado contra los falangistas $»^{20}$. Finalmente, se dan una serie de instrucciones para utilizar al «favorito del Jefe» como juguete inconsciente de las logias ${ }^{21}$.

No es posible afirmar con precisión cuándo fueron elaboradas estas «Máximas». En cualquier caso, fue después del inicio de la segunda guerra mundial, ya que el texto alude a «los países invadidos por el fascismo», y antes de enero de 1941 , fecha en la que varios escritos oficiales aluden al apócrifo por primera vez. Lo más probable es que el documento iniciara su andadura durante la segunda mitad de 1940. Es seguro que a finales de este año ya circulaba en ámbitos restringidos, pues fue cuando el servicio de Recuperación de Documentos, dirigido por Marcelino de Ulibarri, recibió un primer ejemplar. El 13 de enero de 1941, el ya mencionado José Finat enviaba a Ulibarri un segundo ejemplar de este «escrito apócrifo, de elementos que no están encuadrados dentro de las disciplinas del Nuevo Estado.» Ulibarri le contestó diciendo que ya tenía una copia del mismo, pero que desconocía su procedencia. Semanas más tarde, José Lorente, Subsecretario de la Gobernación, remitía a Recuperación de Documentos otra versión de las «Máximas», que él había recibido a su vez del Director General de Prensa. Lorente sabía que el escrito era «análogo a otros que han circulado por ahí», y preguntaba si era un documento auténtico. La respuesta de Ulibarri fue clara: «no creo en su autenticidad.» Añadía además una interpretación de las «Máximas» no muy diferente de la que he propuesto más arriba para el «Mensaje del Gran Oriente»: "no me cabe duda que los autores de este escrito como de otros análogos que hace tiempo circularon son gente desocupada y de no buena intención, cuyo fin no es otro que sembrar el confusionismo» ${ }^{22}$. Finalmente, en julio de 1942, el Tribunal para la Represión de la Masonería remitía a Ulibarri otro ejemplar del documento apócrifo. Curiosamente, el organismo encargado de juzgar a los masones españoles era el único remitente que no cuestionaba la autenticidad del escrito en el oficio que lo acompañaba ${ }^{23}$.

19 He respetado la ortografía y puntuación del original.

20 Máxima 33. A diferencia de lo que se postulaba continuamente en relación a las otras instancias del poder franquista, la posibilidad de introducir adeptos en la Falange es sugerida sólo en dos ocasiones (máximas 58 y 66), y en una de ellas para destacar la dificultad de tal infiltración.

21 Desde el punto de vista formal, las «Máximas» sorprenden por la práctica ausencia de los elementos estilísticos habituales en los documentos atribuidos a la masonería, presentes en el «Mensaje del Gran Oriente» o en el texto de 1943 que veremos después. Ello hace todavía más inverosímil su presunto origen masónico.

22 AGGCE, Masonería, A, leg. 350, exp. 15, 13 de enero, 11 y 12 de febrero de 1941; AGGCE, Exp. Secretaría, 35, 18 de enero de 1941.

23 El texto había sido enviado a dicho tribunal por el Negociado Antimasónico de la Jefatura Superior de Policía de Barcelona. AGGCE, Masonería, A, leg. 350, exp. 15, 29 de julio de 1942. 
La trayectoria seguida por estas versiones de las «Máximas» que llegaron a Recuperación de Documentos muestra que el texto circuló entre finales de 1940 y 1942, por lo menos en distintas esferas del poder franquista. El dictador, siempre curioso ante los escritos «masónicos», también recibió una copia. $\mathrm{Al}$ menos eso parece indicar un informe conservado en su archivo en el que se anunciaba el envío de las «Máximas». Según dicho informe, una joven de la Sección Femenina afirmaría haber descubierto el documento «en la peana de una imagen de Ntra. [sic] Señora, en casa de un señor que ella dice que hace muchos años que es masón. El tal señor se apellida Cortezo, y es médico de la Dirección Gral. [sic] de Sanidad» ${ }^{24}$. Otro ejemplar de las «Máximas» probablemente llegó por esas mismas fechas a la embajada alemana en Madrid ${ }^{25}$.

Hubo al menos un intento por sacar el escrito de esos ámbitos reservados en los que había circulado hasta entonces, para darlo a conocer de manera masiva. Durante la primavera de 1941, los servicios de propaganda, que estaban bajo control falangista, prepararon una edición comentada del documento en una colección que ocultaba su origen oficial. Pero en el último momento se decidió sustituir las «Máximas» por otro supuesto texto masónico mucho menos comprometedor, que apareció en un folleto titulado La masonería en acción. Por muy edulcorada que fuese la versión de las «Máximas» que se pensaba publicar inicialmente, la lectura entre líneas que podía hacerse del documento lo hacía poco apto para el consumo público ${ }^{26}$. Varias décadas después, la administración de justicia del final del franquismo todavía parecía conceder algún valor a esta burda falsificación. En una fecha tan tardía como 1970, el Tribunal Supremo remitía una copia de las «Máximas» a la Causa General, la instancia encargada de reunir las pruebas de los delitos cometidos durante «la dominación roja» 27 .

Además de las cuatro versiones citadas, un quinto ejemplar de las «Máximas» llegó en fecha desconocida a Recuperación de Documentos. AGGCE, Masonería, A, leg. 352, exp. 2.

24 Según el informe, que acompañaba a una carta fechada el 18 de enero de 1942, la falangista sostenía también que «el General Meléndez hizo que llegara a Su Excelencia tal documento, y que la contestación del Caudillo fue: «No interesa, esto ya lo conocía yo».» Pero no podemos saber si la frase de Franco hace referencia a las «Máximas» o a otro escrito citado en el mismo informe. Documentos Inéditos, III, pp. 178-181.

25 Almuiña (art. cit., p. 1007) apunta que Ingrid Schulze ha descubierto en un archivo alemán un ejemplar de las «Máximas» entre la documentación de la embajada correspondiente a 1942. Otro ejemplar acabó en el Servicio Histórico Militar. AGM, caja 2986, exp. 2.

26 El prefacio del folleto seguía anunciando, por un descuido, la reproducción que se pensaba hacer en un principio de las setenta «Máximas». La masonería en acción, Madrid, 1941, pp. 5 y 34. Cfr. Domínguez ARribas, Javier: «La propaganda anti-judeo-masónica durante el primer franquismo: el caso de Ediciones Toledo (1941-1943)», en Ferrer Benimeli, J. A. (coord.): La masonería en Madrid y en España del siglo XVIII al XXI, Zaragoza, 2004, vol. II, pp. 1165-1194.

27 El documento fue archivado en el apartado de «Antecedentes masónicos» relativos al asesinato de José Calvo Sotelo. Archivo Histórico Nacional, Fondos Contemporáneos, Causa General (en adelante, AHN, FC, CG), leg. 1500 (1), fol. 58/1-5. Es la versión que ha sido reproducida y analizada por ALMUIÑA: art. cit., pp. 1006-1027. 
Es sorprendente descubrir que las raíces de un documento de trayectoria tan longeva no se encuentran en 1940, fecha en que probablemente se redactó con la forma que he descrito más arriba, sino más de un siglo antes. Y es que las «Máximas» que hemos visto son en realidad un plagio de otro supuesto documento masónico que había circulado en España de manera clandestina entre finales de 1824 y comienzos de 1825 . Un resumen de estas «Máximas de 1. ${ }^{\circ}$ de Setiembre de 1823» había sido recogido en un folleto titulado Españoles: Unión y Alerta, del que se hicieron varias ediciones en $1824^{28}$. Según las investigaciones llevadas a cabo por la policía fernandina para averiguar el origen de dicha publicación, los responsables de la falsificación eran los canónigos Matías Bravo, Francisco José de Molle y José Salomé García Puente, tres representantes del sector más intransigente del absolutismo ${ }^{29}$. Más de un siglo después, Acción Española realizó una reedición facsímil del folleto, que fue probablemente la que «inspiró» a los falsarios de 1940.

La comparación entre las setenta instrucciones del texto original de 1824 y las también setenta «Máximas» de 1940 puede proporcionarnos una información muy útil acerca de las intenciones de los autores del último documento, por si acaso quedara alguna duda tras la presentación del mismo. En general, los plagiarios se limitaron únicamente a adaptar el texto de principios del siglo XIX al contexto del primer franquismo. Para ello se eliminaron los pasajes que podrían resultar anacrónicos, como los referidos a la Santa Alianza o al periódico El Restaurador. También desaparecen, como es lógico, las alusiones a la monarquía absoluta y al rey, quien se convierte sistemáticamente en «el Jefe», mientras que «los realistas» pasan a ser «los falangistas». Sin embargo, en las «Máximas» de 1940 hay además frases y expresiones que no estaban en el texto original y que tampoco parecen dictadas por la necesaria adaptación al nuevo contexto histórico. Estos pasajes revelan, a mi juicio, la intencionalidad esencial subyacente al documento. Así, entre las escasas máximas de 1940 que no retoman los contenidos de las correspondientes instrucciones de 1824, prácticamente todas dan la consigna de perjudicar a los falangistas y de fomentar su división. En la máxima cuatro, por ejemplo, se ordena evitar «que estos últimos [los falangistas] tengan armas en su poder y a los que por su mérito o talento consignan [sic] algún puesto, se les dará contrario a sus cualidades y condiciones, con objeto de que fracasen procurando que muchos falangistas formen grupitos irreconciliables». A excepción de la última palabra, nada similar aparecía en la máxima correspondiente de Españoles: Unión y Alerta ${ }^{30}$. Otras

28 Españoles: Unión y Alerta. Extracto de un papel cogido a los masones, cuyo título es como sigue: Máximas e instrucciones políticas que el Grande Oriente Español ha mandado poner en ejecución a todas las logias de la Masonería Egipciana, Córdoba, 1824.

29 Véase FuENTES, Juan Francisco: «El folleto «Españoles: Unión y Alerta» (1824)», Trienio. Ilustración y liberalismo, núm. 1, Madrid, mayo de 1983, pp. 27-47.

30 Máxima 4. Aunque yo cito una de las versiones del AGGCE (Masonería, A, leg. 350, exp. 15), puede consultarse también la versión del AHN publicada por ALMUiÑa (art. cit., pp. 1017-1018). 
novedades del documento de 1940 parecen subrayar la idea de la infiltración masónica en la administración de justicia. Así, la ocupación por parte de los «hermanos» de «los ministerios y puestos principales de la nación» se convierte en 1940 en la de «los ministerios y puestos principales de la justicia» ${ }^{31}$. Precisamente, la titularidad de este ministerio estuvo durante estos años en manos de tradicionalistas como el conde de Rodezno o Esteban Bilbao. Finalmente, un último añadido significativo aludía a la propaganda que los masones debían realizar en favor de «la restauración monárquica» ${ }^{32}$. No tendría sentido que un texto de la época de Fernando VII mencionara dicha restauración como un posible acontecimiento venidero, pero tampoco parece casual que los falsarios de 1940 decidieran presentar la defensa de la monarquía como una maniobra masónica. En definitiva, los datos obtenidos a partir de la comparación que acabo de realizar reafirman la impresión resultante de la simple lectura de las «Máximas» de 1940: los autores del documento pretendían sobre todo desacreditar a los adversarios de la Falange en el seno del régimen de Franco. Para ello, no dudaron en recurrir a la siempre útil arma política consistente en identificar con la masonería - de forma más o menos explícita- a todo el que cuestionara a los falangistas, ya fueran instituciones como el Ejército y la Iglesia o familias políticas como los tradicionalistas y los monárquicos.

También era vinculado a las logias - y puesto así en entredicho- «el favorito del Jefe», lo que requiere una explicación suplementaria que nos llevará a los autores de la falsificación. Aunque éstos no habían hecho más que adaptar «el favorito del Rey» que aparecía en el texto de 1824 a las nuevas circunstancias, la figura resultante sólo podía referirse en el contexto de 1940 a Ramón Serrano Súñer. Éste era por lo general considerado como el principal valedor de la Falange en el régimen, pero no todos los falangistas compartían esta opinión. Había también sectores que, insatisfechos ante el nuevo orden de cosas establecido tras la guerra civil, consideraban que el «Cuñadísimo» había traicionado sus expectativas de monopolizar el poder. La elaboración (o mejor dicho, reelaboración) de las «Máximas» se debe sin duda a alguno de estos grupos de falangistas disidentes opuestos a Serrano Súñer ${ }^{33}$. Por tanto, si el «Mensaje del Gran Oriente» era un producto de la disidencia carlista, las «Máximas» lo eran de la falangista. Es posible que los falsificadores estuvieran vinculados a la «Junta Política» clandestina que se había constituido a fines de 1939, no mucho antes de que fuera redactado el apócrifo (segunda mitad de

Cotéjese con Españoles: Unión y Alerta, op. cit., p. 6. Las máximas 3, 6 ó 19 del texto de 1940 contienen otras novedades similares.

31 Máxima 25. Las cursivas son mías. Compárese la versión citada del AGGCE (en esta ocasión la versión del AHN es diferente) y Españoles: Unión y Alerta, op. cit., p. 19. Otros casos similares en las máximas 31 y 42.

32 Máxima 69. Véase en Españoles: Unión y Alerta, op. cit., p. 42; y en ALmuiñA: art. cit., p. 1027.

33 Coincido, por tanto, con la interpretación de AlmuiÑa (art. cit., pp. 1013-1015) acerca de la autoría del documento, pero no con la fecha de elaboración que propone (segundo semestre de 1941). 
1940). Precisamente, esta organización ilegal consideró por esas mismas fechas la posibilidad de asesinar al que las «Máximas» presentaban como el «favorito del Jefe» ${ }^{34}$.

Entre las muchas copias del documento puestas en circulación por esos falangistas disidentes, he localizado siete ${ }^{35}$. Pero no todas son iguales. Como es lógico, la difusión de un escrito no impreso durante un periodo prolongado de tiempo favoreció la degradación progresiva del texto original. Así, son frecuentes las faltas de ortografía, las erratas, reproducidas después por el siguiente copista, y algunas modificaciones en la redacción, por lo general anodinas. Sin embargo, la comparación minuciosa de todos los ejemplares permite también apreciar diferencias más significativas que no pueden ser el resultado del simple descuido del mecanógrafo. Tres ejemplares — de los siete consultados- son muy parecidos entre sí y ligeramente más fieles al folleto plagiado de 1824 , lo que indica que, si no son anteriores, al menos proceden de una versión anterior a la que inspiró los cuatro restantes. Estas cuatro copias que provienen de un foco posterior no tienen muchas diferencias entre sí y se distinguen por llevar todas una nota final firmada con el pseudónimo «Juan de Dios España», ausente en los otros tres ejemplares ${ }^{36}$.

Vemos, pues, la existencia de dos grupos distintos de copias de las «Máximas». La explicación es sencilla: los cuatro ejemplares que creo posteriores - firmados todos con el citado pseudónimo- son el resultado de la introducción intencionada y paulatina en el texto de una serie de modificaciones tendentes a moderar su contenido implícito de carácter falangista radical. Esta acción, que se llevó a cabo desde fechas muy tempranas y por personas perfectamente conscientes del origen apócrifo de las «Máximas», no cambió el sentido general del documento, pero matizó sobre todo - lo que es significativo - la forma en que era presentada la vinculación de la masonería con varios sectores del régimen de Franco. La afirmación «atacaremos principalmente a los fascistas» se convierte en una de las últimas versiones en «atraeremos principalmente a los fascistas», lo que podría ser una errata, si no fuera porque no es el único cambio en este sentido. La supuesta consigna original que ordenaba que «ingresen en falange [sic] si no nuestros adictos», al menos «jóvenes sin principios» pasa a ser la de que «ingresen en Falange nuestros adictos, [...] como también gentes jóvenes y

34 Sobre los falangistas disidentes y la Junta clandestina, véase especialmente PAYNE, Stanley G.: Falange. Historia del fascismo español, [París], 1965, pp. 172-175.

35 Una que terminó en los archivos del Servicio Histórico Militar (AGM, caja 2986, exp. 2), cinco que llegaron a la Delegación del Estado para Recuperación de Documentos (AGGCE, Masonería, A, leg. 350, exp. 15; y leg. 352, exp. 2) y la que fue enviada por el Tribunal Supremo a la Causa General (AHN, FC, CG, leg. 1500/1, fol. 58/1-5).

36 El propio título del documento es ligeramente diferente. En los tres ejemplares que creo anteriores es el ya mencionado de «Máximas e instrucciones políticas para todo el Gran Oriente Español y todas las logias de la masonería egipciana», mientras que en los cuatro restantes desaparecen las palabras que acabo de señalar en cursiva. 
sin principios» ${ }^{37}$. Gracias a estas sencillas modificaciones, las sospechas de infiltración masónica se extendían también a la Falange. Además, una acusación anticlerical muy grave presente en las tres primeras versiones desaparece en las cuatro últimas: los religiosos «conocidos con el nombre de Jesuitas, íntimos amigos nuestros [es decir, de los masones] y enemigos de los católicos y falangistas» se convierten en los mucho más anodinos «Jansenistas, que son amigos nuestros y no de católicos y falangistas» ${ }^{38}$. Por último, la nota explicativa final presente en dos de los tres ejemplares que parecen anteriores no pierde la ocasión de atacar a los enemigos políticos de los falangistas, mediante la consabida vinculación con la masonería. Dicha nota precisa que las «Máximas» fueron encontradas «en el despacho de un médico de mucho nombre y que está bien situado en el campo llamado de derechas ${ }^{39}$. Mientras tanto, la nota final de las otras cuatro copias - firmada por Juan de Dios España - se limita a afirmar que el escrito fue hallado «en casa de un importante masón», sin precisar la filiación política, y además termina haciendo un llamamiento a la unidad frente a la masonería: «Pensad en Dios y en España y venciendo todas las ambiciones y las pasiones, unámonos con fraternidad divina para vencer la confraternidad masónica» ${ }^{40}$.

En suma, las modificaciones introducidas por las sucesivas manos que copiaron el documento transformaron, por ligeramente que fuese, la intencionalidad original con que había sido concebido. Sectores muy diferentes de los que habían puesto en circulación las «Máximas» pudieron intervenir hasta cierto punto en su reelaboración, jugando siempre con el arma arrojadiza que les proporcionaba el discurso antimasónico del franquismo, pero adaptándola a sus propias necesidades, ya fuera neutralizándola o dirigiéndola contra sus propios adversarios. En cierta manera, la falsificación escapó del control de sus propagadores, al igual que un rumor, como si hubiera adquirido vida propia.

\section{La «Palabra Semestral»}

El último documento en el que nos vamos a detener se titula «Palabra Semestral para las Grandes Logias del Oriente de España» y está compuesto por

37 Máximas 33 y 58 . Las cursivas son mías.

38 Máxima 35. En la mayoría de las copias se postula también que las jerarquías eclesiásticas «deberían ocuparse por nuestros amigos», pero en una de las últimas versiones son «nuestros enemigos» los que han de ocupar esos cargos, con lo que desaparece en este punto la idea de la infiltración masónica en la Iglesia. Máxima 32. AGGCE, Masonería, A, leg. 352, exp. 2.

39 Subrayado en el original. AGM, caja 2986, exp. 2. Como vemos, la explicación del hallazgo coincide a grandes rasgos con el informe que Franco recibió sobre el documento.

40 AHN, FC, CG, leg. 1500 (1), fol. 58/1-5; ALmUiÑA: art. cit., p. 1027. La interpretación que este autor hace del ejemplar que analiza es en general correcta, pero a mi juicio insuficiente para las «Máximas» en su conjunto. 
una serie de instrucciones atribuidas a la «Gran Maestría de la Confederación Provisional». El texto está fechado en Lisboa los días 20 y 21 de junio de 1943 y lleva las firmas de Martínez Barrio — como Gran Maestre Español- y de Magalhaes — como Gran Maestre de la citada Confederación Provisional—. En primer lugar, se pide a los militares masones que continúen fomentando el descontento y la discordia en el Ejército. Esa labor de zapa permitirá posteriormente — según el documento - llevar a buen término una segunda directriz de la Gran Maestría que merece ser reproducida textualmente:

Es preciso que, durante el lapso de esta «Palabra Semestral» [es decir, durante la segunda mitad de 1943] [...] se obtenga la Paviada: Una comisión militar, a poder ser de Generales, pero, cuando menos de Jefes del Ejército, ha de asestar el golpe definitivo de la Dictadura Inquisitorial de Franco, presentándose en su Residencia Palaciega — en el momento dado - y conminándole para abandonar el suelo español en el plazo de horas que se fije ${ }^{41}$.

El texto afirma además que las circunstancias internacionales, favorables a los aliados, son idóneas para la instauración de una monarquía democrática, deseable «como mal menor». La orden principal para los masones españoles será entonces la siguiente: "Apoyemos todos la caída de Franco y la subida de Juan III. [...] Y debemos tener en cuenta que el candidato es manejable, por indotado de voluntad» ${ }^{42}$. Con el objeto de lograr una cierta unidad de acción, la Gran Maestría daba además instrucciones para que se prometiera a los distintos sectores monárquicos (liberales, tradicionalistas e incluso falangistas) la realización de sus objetivos políticos, a la vez que se subrayaba la necesidad de captar para el juanismo a los grupos todavía reticentes, como el de Fal Conde. «Resumiendo: Haláguese a los sectores diversos, contrólense las pasiones, y apetencias, preséntese como solución única, la Monarquía Juanista: Falangista?... Tradicionalista?... Liberal, si lo sabemos hacer!»

Este documento fue elaborado entre finales de junio y principios de julio de $1943^{43}$. A mediados de este mes ya había llegado a manos de Franco, probablemente a través de una red de información antimasónica de la que hablaremos más tarde. El dictador parece haber tomado el texto muy en serio, pues ordenó a Luis Carrero Blanco que informara a los tres ministros militares de la conspiración desvelada por la supuesta «plancha» (escrito masónico ${ }^{44}$. El 17 de julio

41 El Español, Madrid, 30 de octubre de 1943, p. 1. El original ocupaba dos páginas mecanografiadas a doble espacio.

42 Ibidem. Subrayado en la reproducción fotográfica del original publicada en El Español.

43 Podemos suponer que el texto fue redactado después del 21 de junio de 1943, última fecha que figura en el documento.

44 El descubrimiento de este documento por parte de Franco es quizá la razón que explica la especial abundancia de alusiones antimasónicas en sus discursos de mediados de julio de 1943. Cfr. FERNÁNDEZ, Carlos: Antología de 40 años (1936-1945), Sada (La Coruña), 1983, p. 135. 
de 1943 se les envió una instrucción reservada, redactada por Carrero y corregida por el propio Franco, que retomaba cada uno de los puntos del documento que acabamos de ver y daba la consigna de no tolerar la más mínima deslealtad al Caudillo, especialmente en el seno del Ejército. Por tanto, se ordenaba a los mandos militares que vigilaran a sus subordinados, «cuidando especialmente las actividades de aquellos que [...] pudieran ser díscolos, descontentos, ambiciosos o sospechosos de afinidad o simpatía con la masonería» ${ }^{45}$.

Existen indicios para pensar que otras copias de la «Palabra Semestral» (además de la que había llegado a Franco) circularon de manera restringida durante los meses siguientes ${ }^{46}$. Pero, a diferencia de los dos casos que hemos visto anteriormente, la difusión del documento dejó de estar limitada a ámbitos reducidos cuando el 30 de octubre de 1943 éste fue publicado en la primera página del semanario falangista $E l$ Español, acompañado de una reproducción fotográfica del original. El texto iba precedido de grandes titulares en los que podía leerse: «La masonería contra España. Nueva conjura para destruir el Caudillaje» ${ }^{47}$. Al día siguiente, numerosos diarios — si no todos— reseñaban elogiosamente el número de El Español que había aparecido la víspera y destacaban la publicación de la supuesta «plancha». Para el influyente Arriba se trataba de «un sensacional documento masónico que demuestra —una vez másla continuidad de los manejos del Gran Oriente contra nuestra Patria» ${ }^{48}$. Unos días más tarde, el 5 de noviembre, diversos periódicos insertaban nuevos comentarios relativos a esas supuestas consignas de la masonería. Arriba, por su parte, volvía a publicar el texto que ya había aparecido en El Español, a la vez que le dedicaba un editorial que sería luego reproducido o comentado en otros periódicos. El día 6 de noviembre era el turno de otros diarios, como $A B C$ o $Y a$, que también transcribían la «Palabra Semestral» ${ }^{49}$.

Tal unidad de acción por parte de la prensa no podía ser casual. Indica más bien que, irónicamente, la única consigna real en este asunto no era de la ma-

45 La instrucción ha sido reproducida por LóPEZ RoDó, Laureano: La larga marcha hacia la Monarquía, Barcelona, 1978, pp. 39-41 (1 ${ }^{\mathrm{a}}$ ed., 1977). Véanse asimismo Tusell, Javier: Carrero. La eminencia gris del régimen de Franco, Madrid, 1993, pp. 92-95; y TOQUERO, José María: Franco y Don Juan. La oposición monárquica al franquismo, Barcelona, 1989, pp. 68-69.

46 Al menos en «ciertos medios madrileños», como apunta SUÁREZ FERNÁNDEZ: op. cit., p. 408. Este autor duda de la autenticidad del documento, al igual que DE LA CiERVA, Ricardo: Historia del franquismo. Orígenes y configuración (1939-1945), Barcelona, 1975, p. 269.

47 El Español, Madrid, 30 de octubre de 1943, p. 1.

48 Arriba, Madrid, 31 de octubre de 1943, p. 4. Véanse, con igual fecha, los diarios madrileños $A B C$ o $Y a$, por ejemplo.

49 Véanse también La Gaceta Regional, Salamanca, 6 de noviembre de 1943, o Amanecer, Zaragoza, 5 y 6 de noviembre de 1943. Este último ha sido reproducido por MORALES RUIZ, Juan José: El discurso antimasónico en la guerra civil española (1936-1939), Zaragoza, 2001, pp. 371-373. Un extracto del documento fue publicado por la prensa alemana el 1 de noviembre, con el objetivo - según las autoridades del Reich — de denunciar la intervención de Estados Unidos y de Gran Bretaña en la política interior española. Documentos Inéditos, IV, pp. 465-467. 
sonería, sino la que había dado la Delegación Nacional de Prensa, ordenando primero la reproducción del documento en un semanario que dependía directamente de ella (El Español) y después la inserción en otros periódicos de comentarios relativos al mismo que insistieran en el tema de la lealtad al Caudillo y de la unidad frente al común enemigo masónico ${ }^{50}$. En 1943, la Delegación Nacional de Prensa, con Juan Aparicio al frente, estaba en manos de falangistas sumisos a Franco, de forma que una campaña como ésta sólo pudo llevarse a cabo con el consentimiento - si no la orden- del dictador. A diferencia de los otros dos casos de textos masónicos apócrifos que hemos visto antes, la difusión de la «Palabra Semestral» —y probablemente su elaboración — no fue una iniciativa de grupos disidentes situados en la periferia del poder, sino que partía de su mismo centro, lo que permitió que esta difusión fuera masiva.

Es evidente que la finalidad principal de esta campaña era neutralizar a don Juan y a sus partidarios, y en particular a aquéllos que pertenecían a las Fuerzas Armadas ${ }^{1}$. Los falangistas leales a Franco que controlaban la prensa utilizaron el tema del supuesto apoyo masónico a este pretendiente como un poderoso instrumento para desprestigiar a los sectores juanistas, una familia política enemiga que también formaba parte de la coalición autoritaria franquista y cuyo ascenso podría restar poder a los falangistas. Los ataques de éstos contra los monárquicos no eran ninguna novedad, pero se habían hecho especialmente necesarios en el difícil contexto de 1943. Las derrotas del Eje hicieron aumentar la incertidumbre acerca del futuro del régimen, lo que a su vez favoreció la movilización de los sectores monárquicos, entre los que figuraban altos mandos militares. Durante 1943, esos sectores llevaron a cabo dos iniciativas de especial trascendencia tendentes al restablecimiento de la monarquía. En junio, veintisiete procuradores de las recién creadas Cortes firmaban una petición en favor de la restauración monárquica. Y es precisamente entonces cuando fue redactado el supuesto documento masónico que nos ocupa, concebido sin duda como una respuesta al escrito de los procuradores. Pero todavía habría que esperar unos meses hasta su publicación. Durante el resto del verano, como consecuencia de la caída de Mussolini a finales de julio, aumentó aún más la inquietud entre los altos mandos del Ejército, hasta el punto de que en septiembre ocho generales sugerían en un escrito dirigido a Franco la conveniencia de una vuelta a la monarquía. Poco después, el 30 de octubre, El Español publicaba las supuestas consignas masónicas que conocemos, entre las que figuraba

so Don Juan alude implícitamente a esta consigna cuando en enero de 1944 se queja ante Franco de «los documentos conteniendo graves acusaciones para mi persona que, obligatoriamente, ha insertado toda la prensa de España». LóPEZ RoDó: op. cit., pp. 522-523.

51 El propio Carrero parece haber advertido, en la circular reservada que hemos visto, los intentos por «inutilizar» a don Juan, pero él los atribuía simplemente a los planes de la masonería. Ibid., p. 40. Además de los falangistas, también los carlistas hicieron uso de la «Palabra Semestral» para desacreditar a don Juan. En 1956, el documento sería publicado en la revista javierista $E l$ Principado. Citada por SuÁREZ FernándeZ: op. cit., p. 408. 
la de que una «Comisión Militar» destituyera al dictador durante la segunda mitad de 1943. Cualquier iniciativa de los generales, por moderada que fuese, quedaba así desacreditada, al ser presentada como el resultado de una maniobra de la masonería. Es decir, la elaboración y la publicación de este documento «masónico» fueron precedidas, respectivamente, por cada una de las dos iniciativas monárquicas de mayor trascendencia que se habían producido durante $1943 \mathrm{y}$, posiblemente, desde el inicio del régimen. El apócrifo titulado «Palabra Semestral» constituye, por tanto, el primer elemento de la reacción emprendida por la Falange de Franco contra la ofensiva monárquica que se había desarrollado durante 1943. La identificación entre masonería y monarquía comenzaba así una larga trayectoria como arma política ${ }^{52}$.

\section{Otros documentos}

Los tres supuestos documentos masónicos que hemos visto no fueron los únicos que circularon en la España del primer franquismo, pero sí los que tuvieron un alcance mayor y, sobre todo, los que hacían una utilización más clara del discurso antimasónico como arma arrojadiza. Serán mencionados brevemente ahora otros documentos atribuidos a la masonería que, a diferencia de los precedentes, o bien no podían ser esgrimidos tan fácilmente contra los grupos que formaban parte de la coalición autoritaria, o bien no obtuvieron prácticamente ninguna difusión. Así, a comienzos de 1940 llegó a conocimiento de Franco (y no sabemos si de alguien más) un supuesto programa de acción masónico que tenía el objetivo final de lograr el restablecimiento de una "República democrática» ${ }^{53}$. El año siguiente, otro escrito similar - ya mencionado más arriba - fue incluido, como sustituto de las «Máximas», en un folleto editado por la Delegación Nacional de Propaganda. Dicho escrito recogía una serie de consignas supuestamente dictadas en abril de 1941 por la Gran Logia Española, entre las que se propugnaba «la desmoralización de la clase obrera» ${ }^{54}$. Meses más tarde, a comienzos de 1942, llegaron al dictador las copias de otros dos documentos, fechados el 22 y el 30 de diciembre de 1941. El primero aludía a la existencia de «hermanos» entre los militares y daba instrucciones para desprestigiar a Franco y a Serrano Súñer, mientras que el segundo texto ordenaba el apoyo incondicional de los masones a Inglaterra ${ }^{55}$. Otra supuesta «plancha» masónica, la «Orden al Gran Oriente de España», fue reproducida

52 En marzo de 1947, por ejemplo, se emitió por radio un artículo escrito bajo pseudónimo por Carrero en el que se vinculaba a la monarquía con la masonería. Tusell: Carrero, op. cit., pp. 168169. Sobre la «ofensiva monárquica de 1943», véanse, por ejemplo, PAYNE, Stanley G.: The Franco Regime 1936-1975, Madison, 1987, pp. 325-332; y DE LA CIERVA: op. cit., pp. 251-270.

53 Documentos Inéditos, II/1, p. 67.

54 La masonería en acción, op. cit., pp. 34-38.

55 SUÁREZ FERNÁNDEZ: op. cit., pp. 298-308. 
en El Español en febrero de 1943, varios meses antes de que el semanario hiciera lo mismo con la «Palabra Semestral». Como ocurrió después con ésta, la «Orden» fue el centro de una campaña de prensa dirigida mediante consignas desde la Vicesecretaria de Educación Popular ${ }^{56}$. Finalmente, Franco recibió el acta de una reunión de la Asociación Masónica Internacional, supuestamente celebrada en Lisboa el 11 de mayo de 1943. Esta vez, el documento relacionaba al SEU con la masonería ${ }^{57}$.

En total han sido presentados, con mayor o menor detenimiento, nueve documentos atribuidos a la masonería. Pues bien, existen indicios para pensar que la mayoría de ellos, incluidas las «Máximas» y la «Palabra Semestral», llegaron a manos de Franco a través de una única red de información que mantenía contacto con Carrero Blanco y que parecía estar especializada en la vigilancia de las actividades masónicas, particularmente en Portugal. La principal informadora en este país se escondía tras las iniciales «A. de S.» y decía ser la mujer de un masón ${ }^{58}$. Es posible que dicha red haya intervenido de una forma u otra en la confección de alguno o de varios de los textos reseñados, especialmente de aquéllos recibidos por Franco en 1942 y 1943. Uno de estos últimos documentos —en concreto el fechado el 22 de noviembre de 1941 — daba una consigna que nos permitirá enlazar con la segunda parte de este trabajo: «hay que seguir, con tiento y sin prodigarlo demasiado, lanzando acusaciones de masonismo contra profanos» ${ }^{59}$. Es decir, según este escrito, los propios masones ya habrían acusado a inocentes de pertenecer a la masonería. ¿En quiénes podían estar pensando los autores de la falsificación?

56 La peculiaridad del documento es que daba a los masones instrucciones para impedir el establecimiento del comunismo en España, lo que, curiosamente, no se ajustaba a un discurso antimasónico oficial que en general subrayaba los vínculos entre comunismo y masonería. El Español, Madrid, 6 de febrero de 1943, p. 1. La consigna que ordena a todos los periódicos la reproducción del escrito, en AGA, Cultura, 21/295.

57 Documentos Inéditos, IV, pp. 233-242. No me cabe duda de que hubo otros documentos masónicos apócrifos que circularon en la España del primer franquismo, y aun durante el resto de la dictadura. En algunos casos, las fuentes sólo mencionan las supuestas consignas de la masonería, sin que sepamos si éstas tenían por origen pretendidas "planchas». Entre muchos otros ejemplos, véase uno en Tusell: Franco, op. cit., p. 244. Por otro lado, ya fuera del periodo que nos ocupa, llegó a manos de Franco otro acta de una supuesta reunión de la AMI celebrada en agosto de 1948. Reproducida en PALACIOS, Jesús: Los papeles secretos de Franco, Madrid, 1996, pp. 40-43.

58 Al parecer, la citada A. de S. transmitía la información a una tal María Dolores Naverán y ésta, a Carrero. En una carta que le envió en octubre de 1943, Naverán aludía a la «Palabra Semestral» y decía que era «un documento que recordará Vd. nos llegó hacía meses». Documentos Inéditos, IV, pp. 506-509. Sobre esta red de información, véanse asimismo Documentos Inéditos, III, pp. 178-181; IV, pp. 225-227, 233-242, 500-505; y SuÁREZ FERNÁNDEZ: op. cit., p. 298.

59 Ibidem, p. 308. La cursiva es mía. 


\section{LOS ATAQUES A PERSONALIDADES CONCRETAS: EL CASO SALVADOR MERINO}

Hemos visto hasta aquí cómo varios sectores del bando vencedor en la guerra civil utilizaron distintos documentos atribuidos a la masonería para desacreditar de manera colectiva a las facciones enemigas que formaban parte de la coalición autoritaria franquista. Pero no fue ésta la única modalidad en el uso del discurso antimasónico como arma política. También era posible afinar más el ataque y dirigirlo específicamente contra personalidades concretas de esas familias políticas enemigas ${ }^{60}$.

Uno de los personajes de más alto nivel que se vio afectado por rumores que le vinculaban a la masonería — sobre todo al final de la guerra civil- fue el jurista Blas Pérez González, que luego iba a ser Ministro de la Gobernación desde septiembre de 1942. Un dictamen suyo de 1939 en contra de un proyecto de ley de represión de la masonería, unido a los contactos que había mantenido en el pasado con personalidades republicanas, le valieron a Pérez González la fama de ser protector y amigo de masones. Se buscaron entonces con tesón - y sin éxito - las pruebas de su pertenencia a la «secta», hasta el punto de que el propio obispo de Santa Cruz de Tenerife tuvo que salir en su defensa ante Franco para contrarrestar los rumores. Éstos finalmente no influyeron en el dictador, pues en 1942 nombró al jurista Ministro de la Gobernación y le conservó en el cargo hasta $1957^{61}$.

El caso que afectó a otro miembro de un gobierno de Franco fue diferente. El monárquico Pedro Sainz Rodríguez, primer Ministro de Educación Nacional del régimen, también fue objeto de persistentes rumores que le relacionaban con la masonería. Sin embargo, no tengo constancia de que tal acusación fuera utilizada por sus enemigos políticos durante el periodo en que desempeñó la cartera de educación, entre enero de 1938 y abril de 1939, ni tampoco antes de su separación definitiva del régimen en 1942. Parece que fue sólo a partir de entonces cuando la supuesta pertenencia a la masonería del político monárquico se convirtió en un argumento para desacreditarle; es decir, una vez que ya no formaba parte de la coalición autoritaria franquista. La persistencia de los rumores se explica porque Franco estaba convencido de que Sainz Rodríguez era masón, lo que quizá ya influyó en el precipitado cese de éste como ministro en abril de $1939^{62}$. La creencia del dictador sólo podía basarse, según el propio

${ }^{60}$ No me ocupare aquí, por tanto, de los innumerables casos de denuncias motivadas por razones meramente personales o profesionales. Véanse algunos ejemplos en AGGCE, Exp. Secretaría, 238.

${ }_{61}$ Blas Pérez no pertenecía de manera clara a ninguna de las grandes facciones que integraban el conglomerado franquista, lo que me lleva a pensar que, en su caso, la acusación de que fue objeto quizá tuviera otras motivaciones además de las estrictamente políticas. Cfr. GARRIGA, Ramón: Los validos de Franco, Barcelona, 1981, pp. 148-156. Véanse también las insinuaciones de DE LA CIERVA: op. cit., p. 158.

62 Tusell (Franco, op. cit., pp. 314-315) no menciona la posible influencia de la creencia de Franco en el cese, pero afirma que éste «no fue justificado en ninguna razón». Sobre la creencia del 
afectado, en dos hechos: la supuesta participación de masones en un homenaje que había recibido en 1924; y su oposición en el Consejo de Ministros a la aprobación de una medida legislativa contra la masonería — rechazada también por Blas Pérez - por juzgarla inoportuna ${ }^{63}$. Lo que quizá no sabía Sainz Rodríguez es que también le relacionaba con la sociedad secreta al menos una carta llegada a Franco a través de la red de información que le proporcionó varios supuestos escritos masónicos ${ }^{64}$. En todo caso, las acusaciones contra el que fue consejero de don Juan e impenitente conspirador monárquico permitían desacreditar a la opción política que representaba y al pretendiente que defendía ${ }^{65}$.

Algo parecido ocurrió con el general Antonio Aranda. Aunque él no era monárquico de principios, intrigó durante la segunda guerra mundial en favor de la opción juanista, al igual que Sainz Rodríguez, y también se rumoreaba de él que había sido masón. En su caso, las sospechas tenían cierto fundamento, pues durante la Segunda República el militar había solicitado su admisión — sin lograrla- en la logia Concordia de Madrid. La documentación procedente de los servicios de Recuperación de Documentos sugiere que existió un gran interés por demostrar de manera efectiva la antigua pertenencia masónica de Aranda, ya que su probada solicitud de ingreso, según Ulibarri, era delictiva únicamente en el «orden interno o espiritual», y no en el procesal ${ }^{66}$. En cualquier caso, el 30 de noviembre de 1942, el héroe del cerco de Oviedo era destituido como Director de la Escuela Superior del Ejército. Su relación con la masonería sin duda contribuyó al cese y al posterior pase a la reserva —en 1949 — del que se había convertido en un peligroso conspirador en contacto con Gran Bretaña ${ }^{67}$.

dictador en el masonismo de Sainz Rodríguez, véase sobre todo Franco SALGado-ARAUjo, Francisco: Mis conversaciones privadas con Franco, Barcelona, 1976, pp. 281 y 418. Al parecer, Franco pidió a Joaquín Arrarás que investigara los antecedentes masónicos de Sainz Rodríguez, pero el historiador de «la Cruzada» no encontró nada. Anson, Luis María: Don Juan, Barcelona, 2003, p. 167 (1 ${ }^{\mathrm{a}}$ ed., 1994).

63 SAINZ Rodríguez, Pedro: Testimonio y recuerdos, Barcelona, 1978, pp. 329-332 y 406-410.

64 Dicha carta, de abril de 1943, mencionaba explícitamente a «Saiz Rodríguez» [sic]. Documentos Inéditos, IV, pp. 225-227. Además, el acta de la reunión de la AMI (11 de mayo de 1943) al que he hecho referencia antes, recibido por Franco a través de este mismo canal de información, aludía a un «hermano Tertuliano» que, al parecer, era identificado por el dictador con este político monárquico. Cfr. Documentos Inéditos, IV, pp. 233-240; LerA, Ángel María de: La Masonería que vuelve, Barcelona, 1980, pp. 141-157.

65 Las sospechas relativas a Pedro Sainz quizá tengan alguna relación con otro rumor similar que afectaba a su amigo Javier Lasso de la Vega, quien había sido nombrado por aquél, durante su mandato ministerial, Director General de Archivos y Bibliotecas. Esta vez los rumores estaban fundados, pues Lasso de la Vega había solicitado ingresar en la logia Isis y Osiris de Sevilla en 1919. Es posible que la referencia del «Mensaje del Gran Oriente» a la infiltración masónica en el cuerpo de bibliotecarios estuviera destinada a atacar a este personaje. Véanse ESCOLAR SOBRINO, Hipólito: La cultura durante la guerra civil, Madrid, 1987, p. 222; y AGGCE, Masonería, B, leg. 277, exp. 25.

66 AGGCE, Exp. Secretaría, 121, 14 de junio de 1943.

67 AGGCE, Masonería, A, leg. 55, exp. 4; Exp. Secretaría, 483; Documentos Inéditos, II/2, p. 420; III, pp. 500-501; IV, pp. 282-289; FERRER BENIMELI, José A.: «Lo que no se ha dicho del general Aranda. 
Aranda y Sainz Rodríguez no fueron los únicos partidarios de la monarquía acusados de tener alguna relación con la «secta masónica». En este mismo sentido, Juan Ignacio Luca de Tena y dos periódicos a él vinculados $(A B C$ y $E l$ Diario Vasco) fueron puestos en cuestión en varias ocasiones por Ernesto Giménez Caballero durante la segunda mitad de 1938. La acusación de estar inconscientemente al servicio de la masonería se produjo en medio de una polémica en la que el componente personal y profesional quizá fuera más importante que el meramente político. Giménez Caballero afirmaba haber sido excluido de $A B C$ por un «achuchón masónico». «No es que A.B.C. sea masón. Pero tiene una gran zona de operaciones para los elegantes y aristocráticos masones de la City», afirmaba el escritor en noviembre de $1938^{68}$. Acusaciones similares afectaron, aunque fuese principalmente después del periodo que nos interesa, a otras personalidades monárquicas como Julio López Oliván, el duque de Alba, Alfonso de Orleáns o el propio Juan de Borbón ${ }^{69}$.

La imputación que nos ocupa también fue utilizada contra algunas personalidades falangistas. En marzo de 1942, el jesuita Enrique Herrera Oria afirmaba en la revista católica Atenas — bajo el pseudónimo de «Hispanicus»que los objetivos en materia educativa del jerarca del Frente de Juventudes Julián Pemartín coincidían con los de la masonería. La acusación se inscribía en el marco de una polémica acerca del creciente papel docente previsto para la organización juvenil falangista, lo que era considerado por los sectores católicos como una amenaza a la autonomía educativa de la Iglesia ${ }^{70}$.

\section{Gerardo Salvador Merino}

El caso paradigmático tuvo por protagonista involuntario en 1941 a otro falangista. Salvador Merino era un «camisa vieja» con pasado izquierdista que durante la guerra civil había desempeñado el cargo de Jefe Provincial de FET

Un ejemplo de represión masónica», Tiempo de Historia, núm. 53, Madrid, abril de 1979, pp. 34-49; SUÁREZ FERNÁNDEZ: op. cit., p. 254. Sobre los contactos de Aranda con los británicos (sobornos incluidos), véanse Ros AGUDO, Manuel: La guerra secreta de Franco (1939-1945), Barcelona, 2002, pp. 148-150; y MARQUiNA BARrio, Antonio: «Conspiración contra Franco. El ejército y la injerencia extranjera en España: el papel de Aranda, 1939-1945», Historia 16, núm. 72, Madrid, abril de 1982, pp. 21-30. Otro general que se vio afectado por rumores similares fue Queipo de Llano. Más conocida es la pertenencia masónica del general Cabanellas, pero falleció antes de que terminara la guerra civil.

68 GiméneZ CABALLERO, Ernesto: «Documento al "ABC" sobre la Monarquía», noviembre de 1938. AGGCE, Fondo Dionisio Ridruejo (en adelante, DR), leg. 5, exp. 5; y exp. 1, 18 de enero de 1939. Véase asimismo TuSELL: Franco, op. cit., pp. 284-285.

69 Véanse SaINZ RodríGUEZ: op. cit., pp. 330-332; y Franco Salgado-Araujo: op. cit., p. 38. Hay insinuaciones acerca del masonismo de don Juan en CARlavilla, Mauricio: Anti-España 1959. Autores, cómplices y encubridores del comunismo, Madrid, 1959, pp. 117-124.

70 Atenas. Revista de orientación pedagógica, núm. 119, Madrid, marzo de 1942, p. 59. Véase el inicio de la polémica en Arriba, Madrid, 21 de enero de 1942, p. 6; y la continuación del asunto en un informe de la DGS de mayo de 1942 reproducido en Documentos Inéditos, III, pp. 501-507. 
en La Coruña, donde se había ganado fama de obrerista (y unos cuantos enemigos). En septiembre de 1939, fue nombrado Delegado Nacional de Sindicatos de FET y de las JONS, cargo desde el que pretendería crear un potente aparato sindical, relativamente autónomo respecto del Estado y capaz de encuadrar a las masas obreras. Meses más tarde se promulgó la Ley de Unidad Sindical (enero de 1940), dirigida a acabar con la autonomía que habían mantenido hasta la fecha las organizaciones católicas agrarias. Mientras tanto, otras medidas despertaron el recelo de los sectores empresariales o de los militares. Para limitar la capacidad de acción de Salvador y aliviar así estas tensiones, Serrano Súñer le propuso cambiar su cargo por el de Ministro de Trabajo, pero al líder sindical no le pareció suficiente. La ambición e iniciativa de éste se pusieron también de manifiesto en las conversaciones que mantuvo con los dirigentes nazis durante su viaje a Alemania en mayo de 1941, ocasión en la que, al parecer, se consideró la posibilidad de realizar un golpe de Estado contra Franco. Al mismo tiempo se desencadenaba en España una grave crisis política que tuvo como resultado la pérdida de poder de los falangistas más radicales en beneficio de aquéllos más sumisos al dictador, lo que debilitó considerablemente la posición del Delegado Nacional de Sindicatos.

En suma, Gerardo Salvador se había creado muchos enemigos en el seno de la coalición franquista, más por sus ambiciosas pretensiones totalitarias y por su inquietante «estilo falangista» de apariencia radical que por las realizaciones concretas de la Delegación Nacional de Sindicatos (DNS), de hecho bastante limitadas. Militares como Varela o Saliquet veían con inquietud la movilización de las masas obreras y una retórica que les recordaba demasiado a la de los «rojos»; la Iglesia temía la pérdida del control sobre las organizaciones agrarias; el mundo empresarial desconfiaba de los intentos por lograr una mayor influencia sindical en la actividad económica; y todo ello por no hablar de los tradicionalistas. Ni siquiera contaba Salvador con el apoyo unánime de los falangistas, y menos tras la crisis de mayo de 1941, ni tampoco con el de Serrano Súñer, muy debilitado desde ese momento y además receloso ante alguien tan ambicioso como él mismo ${ }^{71}$.

Veamos ahora con detalle los pasos que siguieron los adversarios de Gerardo Salvador para deshacerse de él. De hecho, no necesitaron esperar las primeras medidas de éste al frente de la Delegación Nacional de Sindicatos para iniciar el proceso de acoso y derribo. El 11 de septiembre de 1939, sólo dos días después del nombramiento de Salvador, José Finat preguntaba a Marcelino de Ulibarri si en los archivos de Recuperación de Documentos existían antecedentes del nuevo Delegado Nacional de Sindicatos, pues —decía Finat— «según información que obra en mi poder en el año 1932, [sic] pertenecía a una Logia

71 Sobre Salvador Merino y su gestión al frente de la DNS, véanse por ejemplo PAYNE: Falange, op. cit., pp. 176-179; y CHUECA, Ricardo: El Fascismo en los comienzos del régimen de Franco. Un estudio sobre FET-JONS, Madrid, 1983, pp. 361-372. El relato más completo es el de THOMÀs, Joan Maria: La Falange de Franco. Fascismo y fascistización en el régimen franquista (1937-1945), Barcelona, 2001, pp. 189-199 y 253-260. 
que funcionaba en la calle del Príncipe.» La respuesta de Ulibarri fue negativa: «Se ha hecho una revisión de los Boletines Oficiales del Gran Oriente Español desde el año 1914 en mi interés de darle a Vd. una información positiva y nada hemos encontrado» ${ }^{72}$. Poco tiempo después, los esfuerzos del carlista Ulibarri por desentrañar el pasado masónico de un falangista radical como Salvador acabaron por dar fruto: el 5 de diciembre de 1939 comunicaba a Finat, ya Director General de Seguridad, que habían aparecido dos cartas de masones en las que era mencionado Salvador Merino, lo que confirmaba las sospechas existentes. La primera de esas cartas, fechada el 9 de marzo de 1934 y dirigida por un masón de Madrid a otro de Alicante, decía así:

Tengo el gusto de presentarle a nuestro $\mathrm{H} . \cdot$ [hermano] Gerardo SALVADOR MERINO, miembro de nuestra Resp. $\cdot$ Log. $\therefore$ «NOMOS» y además muy amigo mío, que va a esa Capital destinado al Instituto.

Como no conoce Alicante yo le ruego le atienda Vd. con su proverbial fraternidad y le presente a los $\mathrm{HH}$. . de ahí, aunque él, naturalmente, visitará las Log.

En la segunda carta, de 17 de abril de 1934, el destinatario de la primera —un tal Isidro Sánchez_ confirmaba haber recibido «la visita del H. $\therefore$ Gerardo Salvador Merino» ${ }^{73}$.

En diciembre de 1939, el Director General de Seguridad recibió copia de ambas cartas. Y debió de producirse entonces alguna fuga — quizá intencionada- acerca del contenido de las mismas, ya que poco después llegaron rumores sobre la pertenencia masónica de Salvador a un viejo amigo de su familia, Antonio de Correa Veglison, que era Comisario General de Información en el organismo dirigido por Finat. Correa advirtió al dirigente sindical de la existencia de tal rumor y, tras algunas averiguaciones, le informó a principios de marzo de 1940 sobre las cartas y su contenido. Enterado Salvador, Correa informó también a Serrano Súñer y, según el primero, ninguno de los tres concedió la menor importancia al asunto ${ }^{74}$.

No sabemos si el rumor que afectaba a Salvador Merino franqueó los muros de la Dirección General de Seguridad o de otros órganos del poder. Es muy posible. En todo caso, uno de los principales perjudicados por las medidas de la Delegación Nacional de Sindicatos, el dirigente católico-agrario Antonio Monedero, afirmaba en un escrito dirigido en abril de 1940 a diversas personalidades políticas y religiosas que la campaña por el control de las agrupaciones católicas del campo era «completamente coincidente con las instrucciones de la masonería». Los planes del organismo dirigido por Salvador Merino eran así identificados con las consignas masónicas ${ }^{75}$.

72 AGGCE, Masonería, B, leg. 286, exp. 6, 11 y 19 de septiembre de 1939. La cursiva es mía.

73 Las dos cartas, en AGGCE, Masonería, B, leg. 286, exp. 6.

74 AGGCE, DR, leg. 5, exp. 5.

75 CASTILlO, Juan José: Propietarios muy pobres. Sobre la subordinación política del pequeño campesino en España, Madrid, 1979, pp. 415-416. 
Los enemigos del líder sindical decidieron pasar a la acción en junio de 1941. Aunque la maniobra se llevaba preparando desde que Salvador había llegado a la Delegación Nacional de Sindicatos, su puesta en práctica se vio probablemente acelerada tras el viaje de éste a Alemania y la crisis de mayo de 1941, que le había privado de la mayoría de los apoyos que le restaban. Además, en el II Congreso Sindical de junio se había anunciado la integración en el entramado sindical de las cámaras de industria y comercio, una medida que no era sino la gota que colmaba el vaso de los intereses empresariales ${ }^{76}$. Pocos días después de que terminara el citado congreso, el general Andrés Saliquet, en su calidad de Presidente del Tribunal Especial para la Represión de la Masonería y del Comunismo, solicitaba a Recuperación de Documentos los antecedentes masónicos de Salvador ${ }^{77}$. Saliquet llevó entonces la documentación que conocemos a Franco, para confirmar una acusación que ya le había planteado con anterioridad. El dictador mostró entonces las pruebas inculpatorias a sus ministros: "Ahora no se atreverá usted a defender a Gerardo Salvador», parece que le dijo a Arrese, Secretario General del Movimiento ${ }^{78}$. También les pidió su opinión en Consejo de Ministros y, según Serrano Súñer, todos coincidieron en la necesidad del cese ${ }^{79}$. Otra fuente próxima a Salvador sugiere que fue Arrese quien logró que Franco esperara la resolución de la Junta Política antes de tomar ninguna decisión ${ }^{80}$. En cualquier caso, el 23 de julio de 1941 el Tribunal para la Represión de la Masonería abría un sumario contra el Delegado Nacional de Sindicatos ${ }^{81}$. El momento elegido no parece ser casual, pues Gerardo Salvador se encontraba mientras tanto en Mallorca de viaje de novios e ignoraba lo que estaba ocurriendo. Prevenido por sus colaboradores, tuvo tiempo de llegar precipitadamente a la reunión de la Junta Política que debía decidir sobre su caso $^{82}$. El día 5 de agosto tuvo lugar una primera sesión en la que Salvador fue informado de la acusación que se le imputaba y de las pruebas que existían contra él. Al día siguiente, en una segunda sesión de la Junta, entregó a sus miembros un escrito de descargo que merece ser reseñado con detalle.

En él reconocía que en 1934 había llevado a Alicante la carta de presentación de un masón, pero negaba que su contenido pudiera ser el que conocemos, pues nunca había pertenecido a la masonería. Y si se diera valor a dicha carta (en el caso hipotético de que le calificara efectivamente de «hermano»), ello

76 Cfr. THOMÀs: op. cit., pp. 292-294.

77 AGGCE, Masonería, B, leg. 286, exp. 6, 27 de junio y 2 de julio de 1941.

78 Según un informe sin fecha (pero de septiembre de 1941) recibido por Dionisio Ridruejo y probablemente redactado por Germán Álvarez de Sotomayor, principal colaborador de Salvador Merino en la DNS. AGGCE, DR, leg. 5, exp. 5. Véase también SuÁREZ FERNÁNDEZ: op. cit., pp. 65 y 282.

79 SAÑA, Heleno: El franquismo sin mitos. Conversaciones con Serrano Suñer, Barcelona, 1982, pp. $156-157$.

80 AGGCE, DR, leg. 5, exp. 5.

81 THOMÀs: op. cit., p. 295.

82 AGGCE, DR, leg. 5, exp. 5. 
supondría sólo que se había descubierto «el procedimiento [...] para que cesen las personas cuya presencia en determinados cargos molesta o perjudica a conocidos y ciertos enemigos». En su defensa afirmaba además que en 1934 ya formaba parte de Falange y se oponía decididamente a la República y a la masonería. Según Salvador, todo era una maniobra urdida por los enemigos de su gestión al frente de la Delegación Nacional de Sindicatos. Señalaba en concreto al mundo de la gran empresa y no dudaba en implicar también al Intelligence Service y a los anglófilos españoles, deseosos de terminar con un decidido enemigo de los aliados. Irónicamente, Salvador Merino entraba en el juego de sus adversarios y les devolvía la acusación de que era objeto, sugiriendo que la masonería estaba implicada en el complot que se había tramado contra él y contra la Falange. En una ocasión afirmaba que si las endebles pruebas eran tenidas en cuenta,

en mano de los masones se encuentra entonces impunemente el instrumento a propósito y más adecuado para destruir totalmente la Falange y las bases mismas del Estado Español. Aún podría añadir que cada correo de Méjico o de París podría traer implícita una crisis de Gobierno. [...] Resultaría después de todo curioso que el Estado informado por la Falange haya creado una red para coger o inhabilitar a sus enemigos y sean los propios militantes de la Falange, ésta y el Estado los más perjudicados por esa red $^{83}$.

En otro orden de cosas, Salvador afirmaba en su alegato que la competencia para procesar a un miembro de la Junta Política como lo era él, poseedor por tanto de un fuero especial, correspondería en todo caso al Tribunal Supremo y no al Tribunal Especial para la Represión de la Masonería. Finalmente, hacía unas observaciones que merecen ser reproducidas textualmente: «No os llaméis a engaño; lo que aquí se ventila no es un problema personal mío; ni tampoco un problema de depuración del mando político. Lo que aquí se ventila es nada menos que la existencia y la virtualidad política de la Falange.» No le faltaba razón, aunque la cuestión ya estaba solventada desde la crisis de mayo de 1941, momento en que la Falange había dejado de existir en tanto que organización autónoma con un proyecto político propio ${ }^{84}$.

Según el informe de un colaborador de Salvador Merino, el alegato impresionó a la mayoría de los miembros de la Junta, si bien Esteban Bilbao se habría mostrado implacable «en sus diatribas» y Demetrio Carceller, «hostilmente reservado». Era de esperar, pues eran dos de los principales enemigos

83 AGGCE, DR, leg. 5, exp. 5. Más adelante insistía en la misma idea: «Si una voz enemiga y masónica lanza su baba traidora sobre cualquiera de vosotros en un futuro, que por este camino que andamos puede ser próximo, ¿qué haréis entonces? ¿Bastará para vuestro relevo en el servicio de España que la infamia llegue al Tribunal Especial?»

84 Según Salvador, si la Junta admitía que «un problema esencialmente político» fuera resuelto por la vía judicial, entonces lo que hacía era «deponer el mando y el poder político y subvertir el orden de un sistema que todos hemos jurado guardar». AGGCE, DR, leg. 5, exp. 5. Escrito de Salvador, sin fecha (pero del 5 ó 6 de agosto de 1941). 
del Delegado Nacional de Sindicatos. En todo caso, la Junta Política tuvo en cuenta las observaciones de Salvador acerca de la incompetencia del Tribunal Especial para juzgarle y decidió remitir las diligencias al Tribunal Supremo, siempre según el citado colaborador. Arrese comunicó al afectado que la Junta «en ningún caso abandonaría a uno de sus más destacados miembros», por lo que se había decidido mantenerle en su cargo, aunque suspendido de sus funciones. Sin embargo, desde que el Tribunal Especial había solicitado el procesamiento de Salvador a finales de julio, los rumores sobre el masonismo de éste se habían disparado, y fueron en aumento durante el resto del verano, en particular entre sus adversarios políticos ${ }^{85}$. Según Salvador, los propios miembros del Tribunal no habían sido ajenos a este hecho, pues habían revelado "con delectación evidente» secretos que conocían por su cargo. Ante un ambiente cada vez más enrarecido, a principios de septiembre Salvador pidió a Serrano Súñer que aceptara su dimisión. Según el informe de su colaborador, la campaña difamatoria había hecho que Salvador prefiriera renunciar a sus cargos y a la correspondiente condición de aforado para volver a la jurisdicción del Tribunal de la Masonería, con el objetivo de acelerar la resolución del asunto ${ }^{86}$. En efecto, el cese de Salvador como Delegado Nacional de Sindicatos se produjo el 13 de septiembre de $1941^{87}$.

Pocos días antes del cese, un colaborador de Salvador Merino - probablemente Germán Álvarez de Sotomayor, su lugarteniente en la Delegación Nacional de Sindicatos - redactó el informe ya citado. En él explicaba con detalle la totalidad del proceso y censuraba la inhibición de Serrano Súner y de los mandos de Falange, que no habrían hecho nada por cortar la campaña de difamación contra Salvador. El informe consideraba responsables de la maniobra a los enemigos de la Falange, "con evidente apoyo de elementos al servicio de Inglaterra y también de algunos conocidos padres jesuitas», una alusión probablemente referida a Ángel Ayala. Pero, en realidad, el escrito señalaba principalmente a dos hombres. Uno era el carlista colaboracionista Julio Muñoz Aguilar, un enemigo personal —y político - de Salvador desde los tiempos en que éste había desempeñado la Jefatura Provincial de FET en La Coruña. Según el informe, el círculo de Muñoz Aguilar habría difundido bulos acerca del pasado masónico e izquierdista de Salvador, pero también sobre el de otros falangistas como Germán Álvarez de Sotomayor, Gonzalo Torrente Ballester y Jesús Suevos. El segundo responsable de la ofensiva habría sido Demetrio Carceller, Ministro de Industria y Comercio y claro representante de los intereses empresariales. Tras haber fracasado en su intento de someter al Delegado Nacional de Sindicatos

85 Así, el general de simpatías carlistas Heli Rolando de Tella habría afirmado que Salvador ya estaba en la cárcel, por masón, pero también por corrupto (AGGCE, DR, leg. 5, exp. 5). Dicho general había estado vinculado a una de las organizaciones agrarias católicas que fueron sometidas por la DNS. Cfr. CASTILLO: op. cit., p. 419.

86 AGGCE, DR, leg. 5, exp. 5.

87 Según SUÁREZ FERNÁNDEZ: op. cit., p. 282. 
mediante el ofrecimiento de un cargo, no ocultó su hostilidad hacia éste. Así, el informador sostiene que Carceller se «jacta públicamente de ser una de las personas que más han contribuido a que de Gerardo políticamente "no queden ya ni los rabos"». El escrito insinúa además que las pruebas contra Salvador podrían haber sido falsificadas por alguno de los servicios privados de información existentes en Madrid, y en particular por el "grupo de información anti-masónico», el cual mantendría contactos con Manuel de Castro Pena, antiguo secretario del Director General de Seguridad, y con el policía y propagandista anti-judeomasónico Mauricio Carlavilla ${ }^{88}$.

Este grupo — sigue el informe- amañó en cierta ocasión determinadas pruebas masónicas en contra de algunos camaradas de la Dirección General de Seguridad que a lo que parece eran un estorbo para sus manejos, entre ellos el Capitán Coronado y el Capitán González de la Guardia Civil y otros más que al fin sucumbieron ante la campaña que contra ellos se lanzó y en la que ya intervino el General Saliquet.

Además de este militar, también habrían recurrido a los servicios de estos grupos —y sobre todo del antimasónico_ «un padre jesuita de Madrid», una teresiana que era profesora de Carmen Franco y organismos oficiales como la Dirección General de Seguridad o la Casa Militar de Franco ${ }^{89}$. En suma, este revelador informe - que debe ser tomado con la necesaria cautela- sugiere que la fabricación y posterior utilización de falsos documentos masónicos no era ni mucho menos excepcional en la España del primer franquismo.

En octubre de 1941, Salvador Merino fue procesado por el Tribunal Especial para la Represión de la Masonería y del Comunismo, una instancia de la que formaban parte el general Saliquet —como presidente- y Marcelino de Ulibarri, dos de los personajes que más habían hecho por lograr la caída del dirigente sindical. El 23 de octubre era condenado por el delito de masonería a «la pena de doce años y un día de reclusión menor y accesorias de inhabilitación absoluta perpetua y separación definitiva de cualquier cargo». La sentencia tenía en cuenta la «anodina actuación masónica» del acusado, así como sus meritos militares, por lo que se sugería al Gobierno la conveniencia del indulto. Lo curioso es que, si bien las dos comprometedoras cartas tantas veces citadas influyeron en la condena, al parecer fue más concluyente un documento aparecido en el último momento. Dicho escrito, emitido por la Gran Logia Regional del Centro el 10 de abril de 1931, mencionaba que Gerardo Salvador Merino había sido propuesto para ser iniciado en la logia Nomos, lo que probaría que

88 La labor propagandística de Carlavilla le había proporcionado conocimientos suficientes acerca de la documentación masónica auténtica como para fabricar falsificaciones verosímiles. Véase, por ejemplo, uno de sus libros más influyentes: KaRL, Mauricio (pseud.): El Enemigo. Marxismo, Anarquismo, Masonería, Madrid, 1934.

89 AGGCE, DR, leg. 5, exp. 5. 
previamente había solicitado su ingreso en la misma ${ }^{90}$. Salvador interpuso contra la sentencia un recurso que fue desestimado el 8 de noviembre por el Consejo de Ministros, aunque se le conmutaba la pena de reclusión menor — no la inhabilitación- por la de doce años de confinamiento ${ }^{91}$.

No es imposible que Salvador hubiera mantenido contactos con la masonería a comienzos de los años treinta, pero no deja de ser una cuestión secundaria. El hecho indudable es que sus enemigos políticos — desde el general Saliquet a Carceller, pasando por los carlistas Muñoz Aguilar y Ulibarri- removieron cielo y tierra hasta encontrar las débiles pruebas que permitieron defenestrarle. Y es posible que su colaborador no se equivocara al sugerir que éstas podrían haber sido fabricadas. Acabamos de ver que el documento con más peso en la condena había aparecido en el último momento, lo que resulta un tanto sospechoso. Cabe preguntarse cuál era la necesidad de poner en marcha todo este proceso. ¿No habría sido mucho más sencillo lograr un simple cese? Quizá, pero los rumores primero y la acusación después tocaban una fibra sensible de Franco (su obsesión antimasónica), lo que hacía que las garantías del éxito final de la maniobra fueran así mayores. Además, el procedimiento seguido para deshacerse de Salvador permitía algo que su mera destitución habría hecho mucho más difícil de obtener: el descrédito de su labor en el organismo sindical y del equipo con que había contado. La maniobra constituía asimismo una advertencia para todo aquél que en el futuro tuviera veleidades de falangista radical.

La caída de Salvador Merino iba a tener consecuencias muy graves en la Delegación Nacional de Sindicatos. Ante el riesgo de que su lugarteniente, Álvarez de Sotomayor, pudiera seguir la obra de aquél, los enemigos políticos de ambos intentaron repetir la acusación que tan buen resultado había mostrado dar. En agosto de 1941, en medio de la maniobra contra Salvador, el general Saliquet solicitó a Recuperación de Documentos los antecedentes masónicos de Álvarez de Sotomayor, pero resultaron ser negativos ${ }^{92}$. No fue necesario insistir en la búsqueda, pues éste organizó un conato de rebelión entre los dirigentes sindicales provinciales y acabó por ser detenido, inhabilitado y confinado, a causa de su indisciplina ${ }^{93}$. El mismo día del cese de Salvador (13 de septiembre de 1941), Álvarez de Sotomayor era sustituido como Secretario Nacional de Sindicatos por Manuel Valdés Larrañaga, quien fue además investido de las funciones de Delegado Nacional interino. Valdés llevó a cabo una purga en el organismo sindical, destituyendo a numerosos colaboradores de Salvador; algunos fueron sancionados ${ }^{94}$;

90 AGGCE, Masonería, B, leg. 286, exp. 6; y A, leg. 726. La sentencia ha sido reproducida por THOMÀs: op. cit., pp. 296-297.

91 Tras pasar un tiempo desterrado en Calella de Palafrugell (Gerona), Salvador obtuvo un indulto parcial en diciembre de 1944 (se mantenía la inhabilitación) y otro total en 1948. Ibid., pp. 297-299. AGGCE, Masonería, B, leg. 286, exp. 6.

92 AGGCE, Masonería, B, leg. 1012, exp. 26, respuesta de 26 de agosto de 1941.

93 THOMÀs: op. cit., pp. 299-300.

94 Ibidem, pp. 300-301. 
y sobre otros pesó durante cierto tiempo la sospecha de que tuvieran vínculos con la masonería, sospecha que siempre podía ser utilizada en su contra. Durante el año 1942, el haber formado parte del equipo de Salvador era un poderoso argumento a la hora de solicitar los antecedentes masónicos que podían acabar con la carrera política —o profesional— de un falangista ${ }^{95}$.

El escándalo protagonizado por Gerardo Salvador salpicó incluso a alguien tan influyente como Ramón Serrano Súñer, Presidente de la Junta Política y Ministro de Asuntos Exteriores. Al parecer, ni siquiera él escapó al rumor de que era o había sido masón. Eso es al menos lo que Valentín Galarza, Ministro de la Gobernación, comunicaba a Ulibarri en una nota confidencial de octubre de 1941, el mes en que Salvador fue juzgado y condenado. La nota decía así:

El comentario más extendido estos días es sobre la masonería, asegurándose que los alemanes han descubierto todo el fichero de las sectas españolas que dependían de Praga y que allí fué donde se encontró la de Gerardo Salvador Merino. Con este motivo se está extendiendo el rumor de que ha sido encontrada una ficha masónica de Don Ramón Serrano Súñer, haciéndose comentarios sangrientos. [...]

Se insiste en que el Sr. Serrano Súñer es el que defiende a Gerardo Salvador Merino, queriendo relacionar esto en que ambos pertenecen a la secta ${ }^{96}$.

La transmisión de esta nota por parte de Galarza distaba de ser un hecho casual, pues el Ministro de la Gobernación era, además de un antifalangista notorio, un enemigo de Serrano. Contribuía así — sin duda de manera intencionada - a la difusión en medios oficiales de un rumor que quizá fuera muy minoritario en origen. No le faltaba parte de razón a Salvador Merino cuando, en su alegato dirigido a la Junta Política a principios de agosto de 1941, hacía una lúcida reflexión que me servirá para concluir el relato: «nadie, fijaos bien, nadie, ninguna jerarquía política por alta que sea, puede estar libre de que un buen día, en virtud de una acusación de masonería más o menos infundada, sea puesto en entredicho, difamado y procesado por un tribunal de justicia» ${ }^{97}$.

\section{A MODO DE CONCLUSIÓN}

El discurso antimasónico imperante en la España del primer franquismo proporcionó a los distintos sectores del bando vencedor en la guerra civil un

95 Véase un ejemplo en AGGCE, Exp. Secretaría, 394; y otro en AGA, Cultura, 21/143. Otros falangistas que, al parecer, sí habían pertenecido a la masonería eran los periodistas Eugenio Montes y Pedro Mourlane Michelena, pero no tengo constancia de que fueran perseguidos por ello: sin el poder de alguien como Salvador, eran políticamente inofensivos. Véanse, respectivamente, AGGCE, Masonería, B, leg. 629, exp. 17; y AGGCE, Masonería, A, leg. 399, exp. 8.

96 AGGCE, Exp. Secretaría, 238, 17 de octubre de 1941. Irónicamente, el círculo de Salvador reprochaba a Serrano no haber intervenido en defensa del dirigente sindical.

97 AGGCE, DR, leg. 5, exp. 5. 
eficaz mecanismo de descrédito que podía ser empleado contra las facciones enemigas: la identificación de éstas con la masonería. Una modalidad importante en la utilización de este arma política fueron los falsos documentos masónicos, que ya habían mostrado en el pasado su capacidad para fascinar a los medios antiliberales. Hemos visto que los carlistas de Fal Conde se sirvieron de una de estas falsificaciones —el «Mensaje del Gran Oriente»_ para atacar a los falangistas; los falangistas radicales emplearon otra —las «Máximas»contra el conjunto de sus enemigos; los falangistas franquistas esgrimieron la llamada «Palabra Semestral» contra los monárquicos.

La acusación podía abarcar toda una gama de posibilidades: desde insinuaciones más o menos vagas sobre las supuestas relaciones del adversario político con la masonería hasta la idea de la infiltración de ésta en los organismos controlados por el oponente, pasando por la denuncia de la unidad de objetivos. En algunas ocasiones, la acusación era colectiva y difusa; en otras fue lanzada contra personalidades concretas de las familias políticas enemigas, como el falangista Gerardo Salvador Merino. En su caso, la denuncia dio el fruto deseado y tuvo como resultado final la neutralización política del dirigente sindical, tras un proceso meticuloso de acoso y derribo llevado a cabo por sus enemigos.

$Y$ aunque fue un falangista la víctima más importante de este tipo de maniobras, los principales afectados quizá fueron los monárquicos, a causa del pasado más o menos liberal de muchos de ellos, combinado con la asimilación sistemática que en el franquismo se hacía entre liberalismo y masonería. Pero nadie estaba a salvo de ser puesto en entredicho, si bien los tradicionalistas y los políticos católicos gozaban de una cierta protección ante la acusación de masonismo, gracias a un fervor religioso que hacía que los supuestos vínculos con la «secta» fueran especialmente inverosímiles ${ }^{98}$. Un cierto grado de verosimilitud era pues necesario.

En todos los casos, los responsables de la acusación concreta, de la falsificación atribuida a la masonería o de la simple difusión del rumor, recurrían de manera deliberada a un argumento que tenía probabilidades de hacer mella en Franco, dada su conocida obsesión antimasónica. Y Franco era, a fin de cuentas, el árbitro supremo que tenía la última palabra en la resolución de los enfrentamientos intestinos entre los componentes de la coalición autoritaria. Su decisión podía inclinar la balanza del poder en favor de una u otra facción. En estas circunstancias, el rendimiento político de la identificación del adversario con la masonería podía revelarse muy alto. Sin embargo, el mecanismo no estaba exento de riesgos. El caso de las «Máximas» nos ha mostrado que la acusación podía ser modificada y tomar, en cierto modo, vida propia, desviándose

98 Entre los sectores católicos, una excepción la constituyen los miembros del Opus Dei y en concreto su fundador, Josemaría Escrivá de Balaguer. Al parecer, a principios de los años cuarenta fue acusado de masón y denunciado — sin consecuencias — ante el Tribunal para la Represión de la Masonería. Cfr. Berglar, Peter: Opus Dei. Vida y obra del Fundador Josemaría Escrivá de Balaguer, Madrid, 2002, pp. 225-228 (ed. or. alem., 1983). 
así de los cauces trazados por los iniciadores de la maniobra. En otras ocasiones el acusado podía devolver la imputación, convirtiéndose a su vez —o intentando convertirse - en acusador, como hemos visto en el caso de Salvador Merino. Todos podían acusar a todos, pues nadie estaba libre de sospecha.

Por otro lado, el marco autoritario del régimen no hacía posible el debate político ni por tanto la manifestación abierta de las tensiones entre las distintas facciones de la coalición franquista. La lucha fundamental por el reparto del poder a todos los niveles tuvo entonces que expresarse a menudo por medio de la proliferación de rumores, o bajo la forma de «conflictos simbólicos» que giraban en torno a las señas de identidad de cada facción. Otro posible medio de expresión de esas tensiones fue precisamente la identificación, velada o no, del adversario político con la masonería, ya fuera mediante la confección de comprometedores documentos masónicos o a través de acusaciones concretas. Todo esto no excluye que la sospecha generalizada de masonismo fuera al mismo tiempo un eficaz mecanismo utilizado desde el centro del poder franquista para controlar a la posible disidencia existente entre los grupos que componían el conglomerado autoritario. El caso protagonizado por Salvador Merino es, al menos en parte, una buena muestra de ello.

En el contexto del primer franquismo, el discurso antimasónico tuvo también otros usos. Tras haber sido utilizado como un arma política entre las diferentes facciones que integraban la coalición autoritaria y haber contribuido así al ahondamiento de las tensiones y de la división, otra modalidad del mismo discurso fue empleada para lograr exactamente lo contrario: unidad frente al enemigo común. El llamamiento a la unidad ya era una de las principales ideas subyacentes a las propias «Máximas», como respuesta a la supuesta consigna masónica de desunir a los vencedores de la guerra civil. Y habría muchos otros ejemplos, como la campaña de propaganda desarrollada desde finales de 1941 en favor de la unidad entre el Ejército y la Falange, en la que la invocación del común enemigo masónico jugó un papel de primer orden. El discurso antimasónico del régimen mostraría así, una vez más, otra de sus múltiples posibilidades. 